\title{
COVID-19 Süresince İnsanların Sosyal Ağlar Üzerinde Dışa Vurdukları Duygusal Tepkilerin Doğal Dil İşleme Yöntemleriyle Tespit Edilmesi: Ekşi Sözlük Örneği
}

\author{
Detecting Emotional Reactions Expressed by People on Social \\ Networks during COVID-19 by Natural Language Processing \\ Methods: The Ekşi Sözlük Example
}

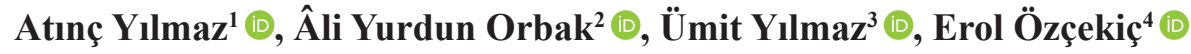

(Dr. Öğr. Üyesi), Beykent Üniversitesi, Mühendislik-Mimarlık Fakültesi, Bilgisayar Mühendisliği Bölümü, İstanbul, Türkiye ${ }^{2}$ (Doç. Dr.), Bursa Uludağ Üniversitesi, Mühendislik Fakültesi, Endüstri Mühendisliği Bölümü, Bursa, Türkiye

${ }^{3}$ (Öğr. Gör.), Balıkesir Üniversitesi, Bigadiç Meslek Yüksekokulu, Yönetim ve Organizasyon Bölümü, Balıkesir, Türkiye

${ }^{4}$ (Öğr. Gör.), Balıkesir Üniversitesi, Bigadiç Meslek Yüksekokulu, Elektrik ve Enerji Bölümü, Balıkesir, Türkiye

ORCID: A.Y. 0000-0003-0038-7519; A.Y.O. 0000-0002-4921-4275;

Ü.Y. 0000-0003-4268-8598;

E.Ö. 0000-0002-1896-6853

\section{Corresponding author:}

Ümit YILMAZ

Balıkesir Üniversitesi, Bigadiç Meslek

Yüksekokulu, Yönetim ve Organizasyon Bölümü,

Balıkesir

E-mail address: umityilmaz@balikesir.edu.tr

Submitted: 05.10 .2021

Revision Requested: 05.12.2021

Last Revision Received: 10.12.2021

Accepted: 10.12.2021

Published Online: 20.12 .2021

Citation: Yilmaz, A., Orbak, A.Y., Yilmaz, U. ve Ozcekic, E. (2021). COVID-19 süresince insanların sosyal ağlar üzerinde dışa vurduklar duygusal tepkilerin doğal dil ișleme yöntemleriyle tespit edilmesi: Ekşi Sözlük örneği. Acta Infologica, 5(2), 319-331.

https://doi.org/10.26650/acin.1004680

\section{Öz}

Dünya Sağlık Örgütü (WHO) tarafından pandemisi ilan edilen ve küresel ölçekte ciddi bir halk sağlığı tehdidi oluşturan COVID-19, tüm dünyayı etkisi altına almıștır. İnsanlık tarihi geçmiște birçok salgına şahit olsa da 21. yüzyıl dikkate alındığında hiçbir salgın COVID-19 kadar etkili olmamıştır. COVID-19'un küresel ölçekte hızlı yayılımı politika yapıcıları ve hükümetleri kısıtlama ve yer yer yasak kararları alma yoluna itmiştir. Bu kararlar neticesinde de insanların sosyal, siyasal, kültürel ve ekonomik hayatlarında önemli değişimler gözlemlenmektedir. Kısıtlamalar ve yasaklar, insanları evlerinde daha fazla vakit geçirmeye itmiş ve insanların evde daha çok zaman geçirmeleri ile internette geçirmiş oldukları süre ciddi derecede artmıştır. Özellikle COVID-19'un insanlar üzerinde yaratmış olduğu hapis durumu, insanların inkâr, korku, öfke, kaygı, kabullenme, güvensizlik, güven şeklinde kategorilendirilebilecek duyguları yoğun bir şekilde yaşamasına ve bu duygularını sosyal medya platformları üzerinden dış çevreleriyle paylaşmalarına yol açmıştır. Bu çalışmada, Türk vatandaşlarının COVID-19 pandemisine has yaşanan olaylara verdikleri duygusal tepkileri değerlendirebilmek adına, Ekşi Sözlük platformunda COVID-19 salgın süreci hakkında açılmış olan çeşitli konu başlıklarından 7500 yorum toplanmış ve Doğal Dil İşleme Teknikleri kullanılarak bir değerlendirme yapılmıştır. Bu değerlendirme aşamasında kelime gömme tekniklerinden olan Word2Vec ve Doc2Vec mimarisinden faydalanılmıştır. Bu teknikler ile Türk vatandaşların verdikleri ortak duygusal tepkiler inceleme altına alınmıştır. Oluşturulan modelin başarısı Word2Vec mimarisinde \%97, Doc2Vec mimarisinde ise \%97,5'lara kadar elde edilmiştir. Anahtar kelimeler: COVID-19, Doğal Dil İşleme, Duygu Analizi, Ekşi Sözlük

\section{ABSTRACT}

COVID-19, which has been declared a pandemic by the World Health Organization (WHO) and poses a serious public health threat on a global scale, has affected the whole world. Although human history has witnessed many epidemics in the past, if we consider just the 21 st century, no epidemic has been as effective as COVID-19. The rapid global spread of COVID-19 has pushed policy makers and governments to implement restrictions and prohibitions. As a result of these actions, important changes were observed in people's social, political, cultural and economic lives. Restrictions and prohibitions forced people to spend more time at home, and as a consequence, the time people spent on the Internet increased significantly. In particular, the forced lockdowns resulting from COVID-19 led people to experience intense emotions such as denial, fear, anger, anxiety, acceptance, insecurity, and trust, and share these feelings with their external environment through social media platforms. In this study, in order to evaluate the emotional responses of Turkish citizens to the events specific to the COVID-19 pandemic, 7500 comments were collected from various topics on the COVID-19 epidemic process on the Ekşi Sözlük platform, and an evaluation was made using Natural Language Processing Techniques. In this evaluation phase, Word2 Vec and Doc2 Vec architectures, which are word embedding techniques, were used. With these techniques, the common emotional responses of Turkish citizens were examined. The success of the model created achieved up to $97 \%$ in Word2Vec architecture and up to $97.5 \%$ in Doc2Vec architecture.

Keywords: COVID-19, Natural Language Processing, Sentiment Analysis, Ekși Sözlük 


\section{GíRiş}

İnsanlık tarihinin başından bu yana insanlar dil yardımı ile iletişim kurmuşlardır. İnsanların iletişim kurarken kullandıkları bu diller doğal diller olarak tanımlanmakta ve dünya üzerinde birçok farklı doğal dil konuşulmaktadır. Makinelerin doğal dilleri anlaması için geliştirilmiş olan yapay zekâ çalışmaları ise Doğal Dil İşleme (DDİ) olarak adlandırılmaktadır (Adalı, 2012). DDİ, doğal dili kullanarak insanlar ve makineler arasındaki etkileşimi geliştirmeye yardımcı olmak için oluşturulmuştur (Phung ve Mimura, 2021). DDİ, klasik dilbilimini geleneksel bilgisayar bilimi ve modern yapay zekâ yöntemleriyle birleştiren çok disiplinli bir alandır. DDİ'nin amacı, makinelerin anlamlı amaçlar için insan dillerini okumasını ve anlamasını sağlamaktır (Luo ve Chong, 2020).

DDİ alanının bir alt dalı olan ve fikir madenciliği olarak da adlandırılan duygu analizi, insanların varlıklara ve yazılı metinde ifade edilen niteliklere yönelik fikirlerini, duygularını, değerlendirmelerini, tutumlarını ve duygularını analiz eden çalışma alanıdır (Liu, 2015: 1). Duygu analizi, öznellik tespiti gibi birçok alt görevi içeren ve metni olumlu, olumsuz ve nötr olarak sınıflandırmayı amaçlayan bir doğal dil işleme ve duygusal hesaplama alanıdır. Duygu analizi, son yıllarda çevrimiçi topluluklar, bloglar, wiki'ler, mikroblog platformları ve diğer çevrimiçi iş birliği ortamlarından elde edilen sosyal medya verilerini işleme konusunda giderek daha popüler hale gelmektedir (Peng vd., 2021). Bundan dolayı duygu analizi çalışmalarında sosyal medya platformlarından toplanan veriler önemli veri kaynakları arasındadır. COVID pandemisi, dünyayı etkisi altına aldığı günden itibaren sosyal medya platformlarında en çok konuşulan konuların başında gelmiş, insanlar bu konu ile ilgili fikir ve değerlendirmelerini farklı sosyal medya platformlarında dile getirmişlerdir.

2019 yılının son günlerinde Çin'de patlak veren ve ardından tüm dünya vatandaşlarının yaşantılarını sekteye uğratan COVID19, 2020 yılının mart ayında WHO tarafından pandemisi duyurulan bir salgın hastalıktır (Özen vd., 2021). Türkiye'de ise COVID-19 kaynaklı ilk tanı 11 Mart 2020 tarihinde koyulmuş, ilk ölüm ise 17 Mart 2020 tarihinde gerçekleşmiştir. WHO tarafından COVID-19 pandemisi duyurulduktan sonra hastalıktan yoğun bir şekilde etkilenen ülkelerde yaşamın eskisi gibi sağlıklı bir şekilde sürdürülebilmesi için çeşitli tedbirler alınmış ve çeşitli kısıtlamalara gidilmiştir (Yetiz, 2021). Covid-19'un çok hızlı bir şekilde insandan insana bulaşması sebebiyle alınan önlemler büyük ölçüde sosyal izolasyonu sağlamaya yönelik olmuştur. Bu sebeple Türkiye'de 12 Mart 2020 tarihinde okullar tatil edilmiş, kamu görevlilerinin yurtdışına çıkışı izne bağlanmış, spor müsabakalarının seyircisiz oynanması gibi kararlar alınmıştır. İlerleyen süreçte toplu aktiviteler sonlandırılmış, uçuşlar durdurulmuş, yurt dışından gelenler iki hafta süreyle karantinaya alınmış, bazı illerde hafta sonları sokağa çıkma yasakları uygulanmaya başlanmıştır. COVID-19 salgını ve salgının yayılmasını önlemek için alınan tüm bu tedbirler insanların hayatını büyük ölçüde etkilemiştir. Alınan tedbirler sosyal izolasyonu sağlamaya yönelik olduğu için insanlar evlerinde çok zaman geçirmiş ve bu durum onların internet ortamında daha fazla zaman geçirip çeşitli platformlarda paylaşımlar yapmasına yol açmıştır. İnsanların hayatlarındaki bu büyük değişiklik hakkında yaptıkları paylaşımlar, büyük bir veri kaynağı oluşturmaktadır.

COVID-19, insanların vücut bütünlüğü üzerinde yarattığı etkilere ek olarak bireyleri psikolojik yönden de etkilemiştir. Hastalığın psikolojik etkilerinin incelenmesi için bilgisayar teknolojilerinden faydalanılabilir. Doğal dil işleme teknikleri bu analizlerin yapılabilmesi için uygun olan tekniklerdendir.

İçinde bulunduğumuz süreçte insanların pandemiyle ilgili duygusal tepkilerinin belirlenmesi amacıyla doğal dil işleme yöntemleri uygulanabilmektedir. Lopez vd. (2020) yaptıkları çalışmada pandemiye verilen ortak tepkileri ve bu tepkilerin zaman, ülke ve politikalara göre nasıl farklılık gösterdiğini belirlemek için doğal dil işleme uygulamalarının kullanılabileceğini belirtmişlerdir. Bu amaçla COVID-19 ile ilgili en fazla konuşulan konuları ve bu konularla ilgili politikaları ele aldıkları çalışmada, Twitter uygulaması üzerinden toplanan ve 22 Ocak- 26 Şubat 2020 tarihlerini kapsayan 6.468.526 tweetten oluşan çok dilli bir veri seti oluşturulmuştur. Araştırmacılar gelecek çalışmalarında topladıkları ve güncellemeye devam ettikleri veri setini NLP, metin madenciliği ve ağ analizi yöntemlerini kullanarak analiz ederek insanların ortak tepkilerini ve bu tepkilerin aradan süre geçtikçe gösterdiği farklılıkları belirlemeyi planlamaktadır.

L. Li vd. (2020) Çin'de oldukça fazla kullanıcısı olan Weibo isimli sosyal medya uygulamasında yer alan COVID-19 içerikli verileri toplayarak sınıflandırma algoritmaları yardımı ile elde ettikleri verileri analiz etmişlerdir. Sınıflandırmada toplanan 
veriler yedi ayrı sınıfa ayrılmış; fakat öğrenme aşamasında sınıf sayısı beşe düşürülmüştür. Öğrenmede yer alan sınıflar duygusal faktörler, algı ile ilgili faktörler, üyelikle ilgili faktörler, kullanıcı ile ilgili özellikler ve içerik ile ilgili faktörler olarak belirlenmiştir. Çalışma sonucunda, etkili sosyal medya temelli acil müdahale programları ve kriz bilgi sistemleri oluşturmayı amaçlayan araştırmacılar veya uygulayıcılar için faydalı olabilecek sonuçlara ulaşıldığı belirtilmiştir.

S. Li vd. (2020), COVID-19’un insanların akıl sağlığı üzerindeki etkilerini araştırdıkları çalışmada; yöneticilere, politikalar geliştirme ve klinik pratisyenlere, süreçten etkilenen topluluklara zamanında hizmet sağlama konusunda yardımcı olabilmeyi amaçlamışlardır. Bu kapsamda 17.865 aktif Weibo kullanıcısının gönderileri makine öğrenmesi yöntemleri ile analiz edilmiş̧ir. Toplanan veriler duygusal (kaygı, öfke vs.) ve bilişsel (sosyal risk yargısı, yaşam doyumu, vs.) göstergelerine göre sınıflandırılmıştır. Araştırmada aynı grubun COVID-19 ilanının öncesi ve sonrasında yaşadıkları farklılıkları incelemek için duygusal analiz ve t-testi yöntemleri kullanılmıştır. Bu analiz sonucunda grupta yer alan kişilerin olumsuz duyguları (kaygı, korku, vs.) ve sosyal risklere karşı duyarlılığ artarken, olumlu duygu puanlarının ve yaşam doyumunun azaldı̆̆ tespit edilmiştir. Bunun yanında insanların sağlıkları ve aileleriyle daha çok ilgilendiği, ev dışındaki sosyal hayatlarını ise daha az önemsedikleri gözlemlenmiştir.

Zhu vd. (2020) ele aldıkları çalışmada, COVID-19 salgınının patlak vermesi neticesinde 24 Ocak 2020 ile 25 Şubat 2020 tarihleri arasında Weibo sosyal medya uygulaması kullanıcılarının paylaşımlarında ifade ettikleri fikir ve duyguların mekânsal-zamansal bir bakış açısıyla duygu analizini gerçekleştirerek duygusal değişimlerin analizine göre, duygu değişimleri sırasında hangi konuların duygular üzerinde olumlu ve olumsuz etki yarattığını tespit etmişlerdir.

Gulati vd. (2021) çalışmalarında, COVID-19 salgını ile ilgili 72000'den fazla tweetten oluşan veri seti yardımıyla duyguların sınıflandırılması amacıyla Pasif Agresif Sınıflandırıcılar, Doğrusal Destek Vektör Sınıflandırması, Çok Terimli Naïve Bayes, Bernoulli Naïve Bayes, Lojistik Regresyon, Ada Boost Sınıflandırıcı ve Perceptron Sınıflandırıcı olmak üzere yedi popüler makine öğrenmesi tekniğinden faydalanmıştır. Daha sonrasında ise kullanılan yöntemler yardımıyla elde ettikleri çıktıları kapsamlı bir şekilde karşılaştırmışlardır. Çalışmanın neticesinde, Ada Boost Sınıflandırıcı dışında uygulanan her sınıflandırııının duyguların sınıflandırılmasında iyi bir doğruluk puanı elde ettiği görülmektedir. Yazarlar ayrıca, COVID-19 gibi salgın hastalıklarla ilgili duyguların incelenmesinin, salgın ve yayılma modelleri hakkındaki önemli bilgilerin tahmin edilmesinde yardımcı olacağı anafikrinde birleşmişlerdir.

Melton vd. (2021), popüler bir sosyal medya platformu olan Reddit'ten 13 alt dizinden toplanan ve analiz edilen metinsel verileri kullanarak COVID-19 aşısı ile ilgili topluluğun duygu ve düşüncesini incelemeyi ve bu duygu ve düşüncelerin aşlara yönelik kamuoyu duyarlılı̆̆ını yansıtıp yansıtmadığını incelemeyi amaçlamışlardır. Bu amaç doğrultusunda 9013 yazar tarafından girilmiş 1401 başlık ve 10240 yorumdan oluşan veri setini temizleyip düzenlemişlerdir. Bu veriler kullanılarak çalışmada duygu analizi ve Latent Dirichlet Allocation (LDA) konu modellemesi uygulanmıştır. Gerçekleştirilen konu modellemesi, topluluk üyelerinin tuhaf komplo teorilerinden ziyade çoğunlukla yan etkilere odaklandığını ortaya çıkarmıştır. Ay bazında gerçekleştirilen duygu analizine göre ise topluluklarda ifade edilen duyguların genel olarak zamanla olumsuzdan daha olumluya doğru olduğu ve sonrasında stabil hale geldiği tespit edilmiştir.

Obembe vd. (2021), çalışmalarında turist kamuoyunun COVID-19 olayına tepkisini ve bu tepkilerin turizm endüstrisi üzerindeki etkisini tespit etmek amacıyla 142491 turist ile ilgili tweet ve 539 ilgili haber makalesi incelemiş; sosyal aracılı kriz iletişim modelini kullanmışlardır. Çalışmanın metodolojisinde, kriz sırasında meydana gelen iletişimlerin kamu algıları üzerindeki etkisine ilişkin fikir edinmek için duygu analizinden faydalanılmışıır.

Bu çalışma kapsamında insanların hayatlarında meydana gelen büyük değişim ve COVID-19 pandemisi hakkındaki duygularını analiz etmek adına Ekşi Sözlük platformundan pandemi ile ilgili olan farklı konu başlıklarına ait kullanıcı yorumları toplanmıştır. Bu yorumlar DDİ yöntemleri kullanılarak değerlendirilmiş ve pandemi sürecinin duygusal etkileri analiz edilmiştir. Bu çalışmadan yola çıkılarak belirlenen duygular ışığında toplumsal olaylarla ilgili insanların duyguları ve verdikleri ortak tepkiler tespit edilebilir. Elde edilen sonuçlar süreç içerisinde karar vericiler tarafından izlenecek politikaların tespitinde yol gösterici bir faktör olabileceği düşünülmektedir. Bunun yanı sıra Türkçe dilinde oluşturulan model ve sınıflandırma otomatik duygu tespiti için alt yapı oluşturabilecek niteliktedir. 


\section{MATERYAL VE METOT}

Bu çalışmada benimsenen araştırma metodolojisi, Şekil 1'deki akış şemasında gösterilen dört ana adımı izlemektedir.

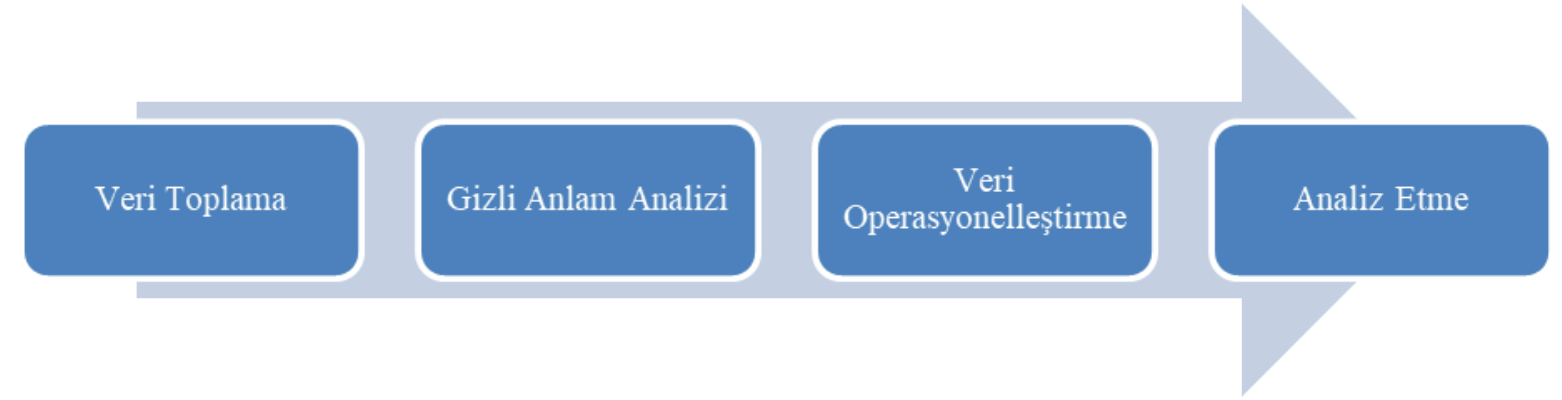

Şekil 1. Araştırma metodolojisi adımları.

\subsection{Veri Setinin Tanıtılması}

Sözlük, alfabetik sıralaması yapılarak bir dil ile ilgili tüm veya belirli zamanlar içerisinde kullanılan sözcüklerin ve deyimlerin tanımlarının yapıldı̆̆ başlayarak tablet sözlük, sözlü sözlük, basılı sözlük ve dijital sözlük olarak çeşitli aşamalardan geçmiştir (TDK, 2021; Kaya, 2020). Dijital sözlüklerden biri olan katılımcı sözlük, yazar olarak adlandırılan katılımcı bireylerin çeşitli konular hakkında etkileşime girerek yorumlarda bulundukları internet sitesidir (İşleyen, 2019). Türkiye'de hayata geçen ilk katılımcı sözlük olan Ekşi Sözlük, oldukça geniş bir yazar grubuna sahip olan, bu yazarların her tip kavram hakkında yorumlarını içeren ve Türkiye'de en çok tanımlama yapılan bir internet platformudur (Altintaş vd., 2019). Ekşi sözlük, alışılagelmiş sözlükler gibi bir konu başlığı hakkında tanımlamalar yapılmış bir yapıdan ziyade, yazarların açtı̆̆ı konu başlı̆̆ının altında birçok yazarın fikirlerini beyan ettiği dinamik bir yapıdadır. Ekşi sözlük yönetimi, aynı kapsamda olan ve birbirine benzer başlıkların açılmasına ve bu başlıklar altına yorumlar girilmesine imkan tanımaktadır (Porsuk ve Cerit, 2021).

Bu çalışmada, Türkiye'de ilk COVID-19 tanısının bildirildiği 11 Mart 2020'den 31 Mart 2020’ye kadarki süreçte toplumun pandemi ile ilgili duygu ve düşüncelerin incelenmesi için Ekşi Sözlük platformundan pandemi ile ilgili farklı konu başlıkları belirlenmiş ve bu başlıklar altındaki kullanıcı yorumları toplanmıştır. Bu konu başlıklarından bazıları "corona virüsü sayesinde fark edilen gerçekler (EkşiSözlük, 2020a)”, “covid-19 (EkşiSözlük, 2020b)”, “covid-19 salgınını hafife alanlar (EkşiSözlük, 2020c)”, “çocuk kişisiyle karantina günleri (EkşiSözlük, 2020d)”, "koronavirüs (EkşiSözlük, 2020e)”, “sarscov-2 (EkşiSözlük, 2020f)” ve “sokağa çıkma yasağı (EkşiSözlük, 2020g)” şeklinde sıralanabilir. Tespit edilen konu başlıklarına ait kullanıcı yorumları, Python dilinde yazılmış bir web örümceği olan Scrapy ile edinilmiş ve virgülle ayrılmış değer dosyası formatında kaydedilmiştir. Veri toplanırken kullanıcıların kişisel verileri hariç tutulmuştur.

\subsection{Gizli Anlam Analizi}

Gizli anlam analizi, cümle veya paragraf başına bir kelime sayısı matrisi doldurarak başlar. Her sütun bir cümleyi veya paragrafı temsil eder ve her satır benzersiz bir kelimeyi temsil eder. Bu analizde, sıralar arasındaki benzerlik yapısını koruyarak sütun sayısını azaltmak için iyi bilinen bir boyut azaltma yöntemi olan Tekil Değer Ayrıştırma (Singular Value Decomposition - SVD) kullanılmaktadır. Kelimeler, sıfır ile bir arasında değişen iki vektör arasındaki kosinüs benzerliği hesaplanarak eşleştirilir (Suleman ve Korkontzelos, 2021: 2).

Gizli anlam analizinin işlem adımları Şekil 2'de gösterilmiştir: 


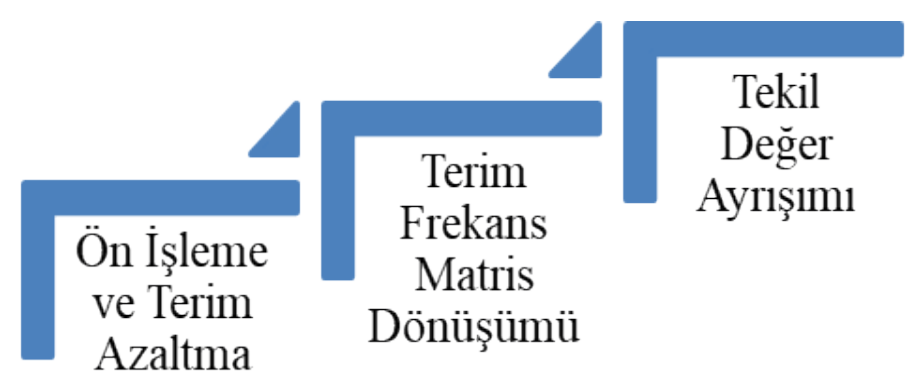

Şekil 2. Gizli anlam analizi işlem adımları.

Önişleme ve terim azaltma olarak adlandırılan ilk adımda, neredeyse tüm yorumlarda (makaleler ve yardımcı fiiller) kullanılan, ayırt edici gücü olmayan ve dolayısıyla indeksleme sürecinde çıkarılması gereken terimler silinmiştir. Veri seti üzerinde ön işleme ve terim azaltma aşamaları Python programlama dili kullanılarak gerçekleştirilmiştir. Çalışmanın veri ön işleme ve terim azaltmaları aşamaları aşağıdaki gibi sıralanabilir:

• RegEx modülü kullanılarak noktalama işaretleri ile veri içinde çokça karşılaşılan “@”, “\#” ve "\&” gibi karakterler temizlenmiş, kelimeler küçük harfe dönüştürülmüş ve yorumlar boşluklar temel alınarak kelimelere bölünmüştür.

- Türkçe dilinde yaygın olarak kullanılan bağlaçlar ile tek başına bir anlam ifade etmeyen ve literatürde durak kelimeleri (stop words) olarak adlandırılan 292 adet kelimeden oluşan bir liste kullanılarak durak kelimeleri veri setinden ayıklanmıştır. Bu kelimelerin veri setinden çıkarılmasının temel amacı konu ile ilgili olan daha değerli kelimeleri bulabilmektir. Durak kelimeleri çıkarıldıktan sonra tüm kelimeler birleştirilerek bir derlem (corpus) elde edilmiştir.

İkinci adım, terim frekans matrisi dönüşümüdür. Terim frekans matrisi, frekansları normalleştirmek için ters doküman matrisi ile çarpılmaktadır. Bahsi geçen çarpım sonucunda elde edilen matris TF-IDF matrisi olarak bilinmektedir (Kundu vd., 2015). TF-IDF, kelimelerin ağırlıklarının ayarlanmasında yardımcı olmaktadır. TF-IDF, herhangi bir terimin ağıllığını belgedeki oluşumlarının sayısına ve derlemdeki terim sıklığı ile dengelemeye bağlı olarak orantılı olarak artırmak için bir ağılık faktörü olarak kullanılır. Bu sayede dokümanlarda sık tekrarlanan kelimeler yerine, daha az tekrarlanmakla birlikte dokümanları daha başarılı temsil edebilecek kelimelerin ve kelime gruplarının belirlenmesi sağlanmaktadır. TD-IDF'de izlenen yaklaşım Denklem (1)'de gösterilmiş̧ir. Denklemde $T F-I D F_{i j}$ elde edilen ağırlığı, $t f_{i j}$ terim frekansını, $d f_{i}$ derlemdeki doküman sayısını, $N$ toplam doküman sayısını ve $\log \left(\frac{N}{d f_{i}+1}\right)$ ters doküman matrisinin logaritmasını temsil etmektedir (Singh ve Modi, 2019).

$$
T F-I D F_{i j}=t f_{i j} \times \log \left(\frac{N}{d f_{i}+1}\right)
$$

Üçüncü adımda, TF-IDF matrisinin boyutluluğunu azaltmak için bir Tekil Değer Ayrıştırma (SVD) tekniği uygulanır. Bu çalışma kapsamında Python dilindeki Sklearn Kütüphanesi içerisinde bulunan ve gizli anlam analizi metotlarından biri olan TruncatedSVD yöntemi kullanılmıştır. TruncatedSVD, tekil değer ayrıştırması (TDA) ile doğrusal boyut indirgeme gerçekleştirmektedir. Kullanılan algoritmanın parametre değerleri denenerek belirlenmiştir. Veri seti için optimum sonuç veren küme ve iterasyon sayıs1 10 olarak seçilmiş ve algoritma parametresi randomized-rassal olarak belirlenmiştir. Üçlü kelime gruplarının belirlenebilmesi için TF-IDF ngram parametresi 3 olarak kullanılmıştır.

Veri üzerinde TruncatedSVD yöntemi uygulandıktan sonra ortaya çıkan bazı konu başlıkları "virüsü ciddiye almıyorum", "panik yapmayin", "sokağa çıkma yasağı gelmeli”, "geçmiş olsun", "maalesef geldi korkuyorum", "erzak depolamak gerizekalılık yapmayın”, "ahlaksızlara gün doğuyor”, "büyük yüzdesine bulaşacak”, "umudum kalmadi elveda dünya”, "açıklanmıştır allah yardımcımız", "sokağa çıkma yasağı gelmezse sonumuz vahim", "artıyor kötüsü alışıyoruz”, "güven veren bakandır", "inandırıcı gelmeyen açıklamadır verilere güvenmiyorum" ve "lütfen sokağa çıkma yasağı gelsin" şeklinde siralanabilir. 


\subsection{Veri Operasyonelleștirme}

TruncatedSVD yöntemi uygulandıktan sonra ortaya konu başlıkları incelendiğinde yorumların inkâr, korku, öfke, kayg1, kabullenme, güvensizlik, güven gibi duyguları barındırdığı görülmektedir. Kullanıcı yorumlarının bu duygulara karşılık gelen kelimelerle etiketlenme işlemi yapılırken ilgili duyguların literatürdeki tanımlarına sadık kalınmıştır (Bekaroğlu, 2019; Dan-Glauser ve Gross, 2015; Gençöz, 1998; Soykan, 2003; Ünal Karagüvan, 1999). Örneğin "virüsü ciddiye almıyorum" konu başlığı inkâr duygusunu barındırırken "maalesef geldi korkuyorum" konu başlığı korku duygusunu, "sokağa çıkma yasağı gelmezse sonumuz vahim" konu başlığı kaygı duygusunu içermektedir. Veri setindeki yorumlar incelenirken korku, kaygı, beklenti, inkâr gibi duyguları içeren yorumların yanı sıra sürecin gidişatının iyi olacağı, uygulanan politikaların yerindeliği, tedavi süreçlerine ilişkin iyimser yaklaşımlar gibi görüşleri içeren yorumlara da rastlanmış ve bu yorumlar "olumlu duygular" etiketi altında modele dâhil edilmiştir.

Belirlenen duygular doğrultusunda kullanıcı yorumları etiketlenmiştir. Bu etiketleme işleminin yapılmasındaki temel amaç, dinamik olan bu süreç içerisinde daha sonraki dönemlere ait verilerin elde edilen sınıflara otomatik olarak atanmasını sağlamak ve pandemi ile ilgili otomatik bir duygu tespiti yapmak için alt yapı oluşturmaktır.

\subsection{Analiz Etme}

Makine öğrenmesi algoritmaları, metin madenciliği için dizgi biçimindeki ham metni işleyemez. Bu sınırlama, sınıflandırma, regresyon analizi, bilgi çıkarma, duygu analizi gibi çeşitli metin işlemlerini gerçekleştirmek için ham metinleri sayısal temsillere dönüştürerek ele alınabilir (Khatua vd., 2019). Kelime gömme, bir kelime dağarcığındaki kelimeyi veya kelime öbeklerini gerçek sayı vektörleriyle eşleştiren bir dizi tekniktir. Buradaki fikir, anlamsal olarak benzer kelimelerin yakın vektörlere atanacağıdır, böylece model bazı kelimeler hakkında öğrenilen bilgileri diğer benzer kelimelere aktarabilir. Bu durum kelime başına bir boyutlu ayrı bir atomik semboller uzayını daha düşük boyutlu sürekli bir vektör uzayına dönüştürmeye eşdeğerdir. Bu, metnin çok daha kullanışlı ve izlenebilir bir temsilidir. Kelime gömme işlemleri tipik olarak sözdizimsel ayrıştırma, dil modelleme ve anlamsal olarak ilişkili kelimeleri tahmin etme gibi görevlerde doğal dil işleme bağlamında metinlere uygulanır (López vd., 2020). Çalışmada kelime gömme için Word2Vec ve Doc2Vec mimarisinden faydalanılmıştır.

\subsubsection{Word2Vec Mimarisi}

Mikolov vd. (2013) bir kelimeyi belirli bir pencere boyutunda çevreleyen kelimelere göre analiz etmek için Word2Vec modelini tasarlamıştır. Pencere boyutu, çevreleyen kelimelerin uzunluğudur ve kullanıcı tarafından seçilir. Word2vec, iki kelimenin bir arada bulunma olasılığının daha yüksek olması, kelimeler arasında daha yüksek benzerlik olduğu varsayımına dayanmaktadır. Word2vec, çevreleyen sözcükler göz önüne alındığında merkezi sözcügün oluşma olasıllğını en üst düzeye çıkarır (H. J. Kim vd., 2020).

Word2vec, kelime vektörleri oluşturan en iyi bilinen kelime gömme algoritmalarından biridir. Word2Vec modeli, belgedeki her kelimenin vektör temsilini oluşturur. Böylece benzer anlama sahip kelimeler bir vektör uzayında yakın noktalara adreslenir. Dağılım hipotezlerine dayanarak, Word2Vec modeli, benzer bir bağlamda ortaya çıkan kelimenin benzer anlama sahip olduğunu varsayar. Word2Vec, sinir ağının girdisine ve hedefine göre Continuous Bag of Words (CBOW) ve SkipGram (S-G) olmak üzere iki türe ayrılabilir. CBOW tekniği, her bir kelimenin bağlamını bilgi olarak alır ve belirli bağlamla ilgili kelimeyi öngörmeye çalışır. Bağlam, tek bir kelime veya bir kelime toplamı olabilir. Bağlam kelimeleri, tek sıcak kodlama kullanılarak bir vektöre dönüştürülür. S-G ise istatistiksel dil modellemesi için basit sinir ağı mimarisini kullanarak kelime temsillerini öğrenmektedir. S-G’de eğitim amacı, aynı cümledeki kelimenin bağlamını tahmin ederek bir kelimenin temsilini öğrenmektir. CBOW modelinde, girdi bağlam kelimelerinin ortalamasıdır ve hedef merkez kelimedir. S-G'da ise girdi merkez sözcüktür ve hedef her bağlamsal sözcüktür. CBOW, sık kelimelerin modellenmesinde daha iyi kabul edilirken, S-G ise seyrek kelimeleri modellemek için daha iyi kabul edilir. Her iki modelde de önceden tanımlanmış uzunlukta bir pencere derlem boyunca hareket ettirilir ve her adımda ağ, pencerenin içindeki sözcüklerle eğitilir (Altszyler vd., 2017; Choi ve Lee, 2020; Hu vd., 2019; Jha vd., 2020; Shobana ve Murali, 2021; Yen vd., 2019). CBOW ve S-G modeli mimarisi Şekil 3’te gösterilmiştir (Mikolov vd.,2013). Çalışmada CBOW model mimarisinden faydalanılmıştır. 


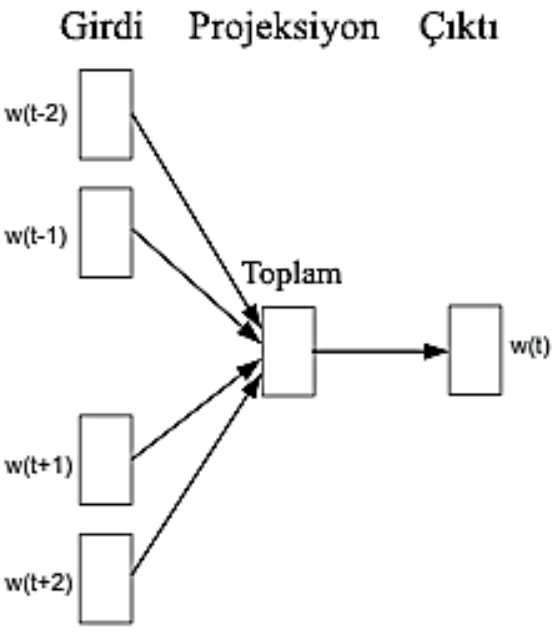

a) $\mathrm{CBOW}$

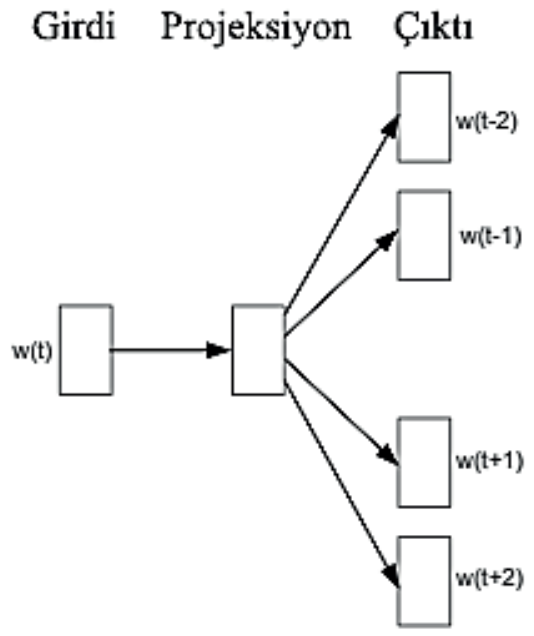

b) S-G

Şekil 3. CBOW ve S-G modeli mimarileri.

Bir cümle içinde eğitilmiş $w_{1}, w_{2}, w_{3}, \ldots w_{T}$ kelimeleri göz önüne alındığında, kelime vektör modelinin amacı, logaritmik olasılıkların maksimum ortalamasını türetmektir. İlgili durum Denklem (2)'de gösterilmiştir.

$$
\frac{1}{T} \sum_{t=k}^{T-k} \log p\left(w_{t} \mid w_{t-k}, \ldots, w_{t+k}\right)
$$

Öngörücü görevler, softmax gibi çok sınıflı bir sınıflandırıcı kullanılarak yapılır. İlgili durum Denklem (3)'te gösterilmiştir.

$$
p\left(w_{t} \mid w_{t-k}, \ldots, w_{t+k}\right)=\frac{e^{y_{w_{i}}}}{\sum_{i} e^{y_{i}}}
$$

Her $\mathrm{y}_{\mathrm{i}}$, kelime vektörü çıktısı için yapılandırılmamış bir olasılıktır. İleri beslemeli bir sinir ağının y çıktı değeri Denklem (4) yardımıyla belirlenmektedir. Denklemde b, gizli katman için bias ifadesini, U gizli katmandan çıkış katmanına olan bağlantılardan oluşan ağılık matrisini, h W matrisindeki ortalama kelime vektörünü ve $\mathrm{W}$ kelime gömme matrisini ifade etmektedir. Ayrıca denklemde U ve b softmaxin parametreleri olarak fonksiyon görmektedir (Chang vd., 2018: 657).

$$
y=b+U h\left(w_{t-k}, \ldots, w_{t+k} ; W\right)
$$

\subsubsection{Doc2Vec Mimarisi}

Word2Vec mimarisinin başarısından esinlenen Le ve Mikolov (2014), Word2Vec mimarisini her bir doküman için paragraf vektörü veya doküman gömme olarak bilinen bir vektör gösterimi üreten Doc2Vec mimarisine genişletmiştir. Yazarlar, ele aldıkları çalışmalarında Doc2Vec mimarisini bir dokümanın yoğunluk vektörünü çıkarmak için kullanmayı önermişlerdir. Doc2Vec, mükemmel ölçeklenebilirliğe sahiptir ve kelimelerin anlamlarının göz ardı edildiği önceki yaklaşımların boşluklarını doldurmuştur. $\mathrm{Bu}$ yaklaşımın amacı, uzunluğuna bakılmaksızın bir dokümanın sabit uzunlukta sayısal bir temsilini oluşturmaktır. Doc2Vec, her bir doküman için, her boyutun bir özellik olarak yorumlanabileceği n boyutlu bir vektör sağlar. Doc2Vec, sabit olmayan uzunluktaki bir dokümanı bir vektöre dönüştürür ve bu dokümanın her kelimesini birleştirir (Tahvili vd., 2020).

Doc2Vec modeli iki farklı ögrenme mimarisine sahiptir. Paragraf Vektörünün Dağıtılmış Bellek Sürümü (Distributed Memory version of Paragraph Vector - PV-DM) öğrenme modeli Word2Vec modelindeki CBOW model mimarisine, Paragraf Vektörünün Dağıtılmış Kelime Çantası Modeli (Distributed Bag of Words-Paragraph Vector - PV-DBOW) de Word2Vec modelindeki S-G model mimarisine karş1lık gelmektedir (Kınık ve Güran, 2021). PV-DM'de model, küçük bir pencerede bağlam kelimelerini ve paragraf vektörünü kullanarak merkez kelimeyi tahmin etmek üzere eğitilir. Öte yandan, PV-DBOW mimarisinde paragraf vektörü, bağlam sözcüklerini doğrudan tahmin etmek için eğitilir (Sanz, 2020: 4). Her iki model mimarisinin kavramsal çerçevesi Şekil 4’te gösterilmiştir (Le ve Mikolov, 2014). PV-DM modeli çoğunlukla, daha zayıf 
genellemeye yol açan çok yüksek boyutlu bir temsil oluşturan PV-BOW modellerinden daha iyi performans gösterir (Sanz, 2020). Bundan dolayı bu çalışmada, sınıflandırma performansını iyileştirmek için Doc2Vec modelinin birincil yapısı olan PV-DM eğitilmiştir.

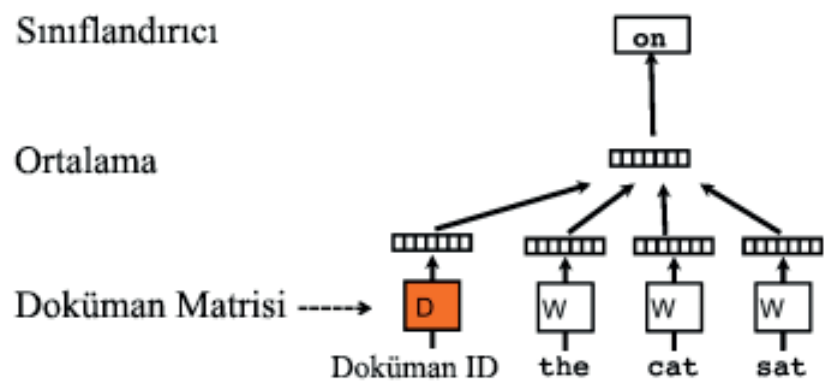

a) PW-DM

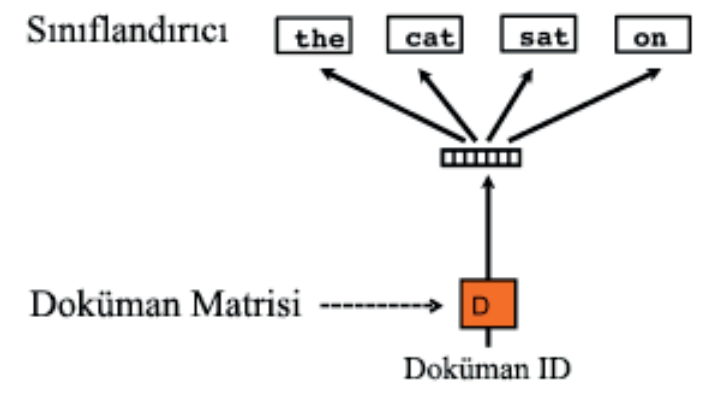

b) PW-DBOW

Şekil 4. PV-DM ve PV-DBOW'un kavramsal çerçevesi.

Doc2Vec'de her doküman, eşsiz bir vektör olan D matrisindeki bir sütunla; her kelime ise W matrisinde bulunan bir sütun olan eşsiz bir vektör ile eşleşmektedir. İleri beslemeli bir sinir ağının y çıktı değeri Denklem (5) yardımıyla belirlenmektedir. Denklemde b, gizli katman için bias ifadesini, U gizli katmandan çıkış katmanına olan bağlantılardan oluşan ağırlık matrisini, h bağlam sözcükleri için ortalama veya birleştirme, W kelime gömme matrisini ve D doküman matrisini ifade etmektedir (D. Kim vd., 2019).

$$
y=b+U h\left(w_{t-k}, \ldots, w_{t+k} ; W, D\right)
$$

\section{BULGULAR VE TARTIŞMA}

Veri setinde yer alan tüm yorumlar etiketlendikten sonra etiketlerin yorum sayılarına ait sayısal dağılım grafiği Şekil 5’te gösterilmiştir. Şekil 5, 2020 Mart ayı içerisinde insanların yaptıkları yorumların hangi duygulara ait olduğunu sayısal olarak ifade edilmektedir. Şekil incelendiğinde en ağır basan duygunun öfke olduğu ve bunu takip eden duyguların sırasıyla beklenti, kaygı ve güvensizlik olduğu görülmektedir.

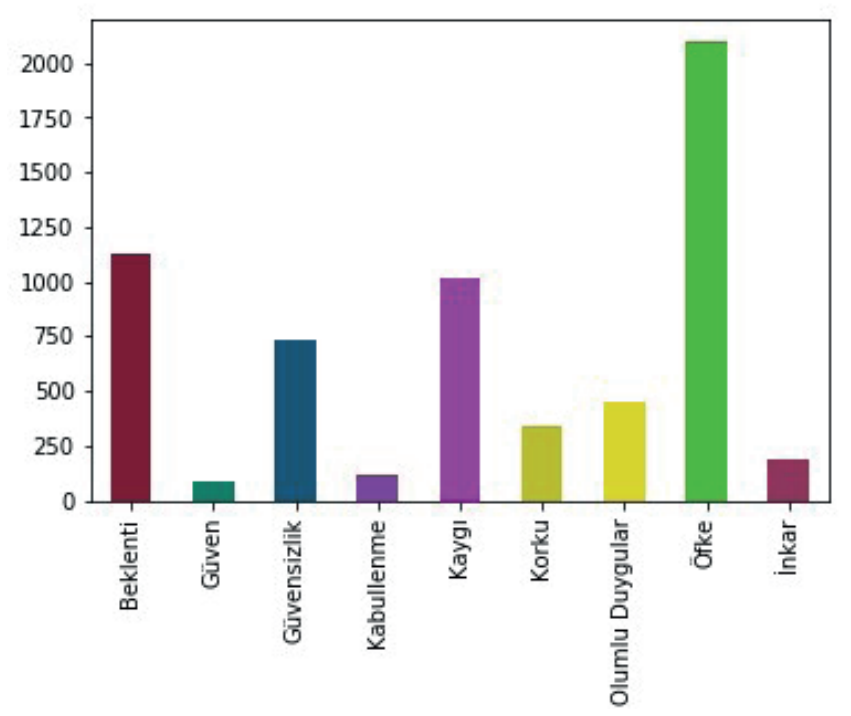

Şekil 5. Duygu etiketlerinin sayısal dağılım grafiği.

Veri setinden elde edilen derlem üzerinde yapılan analiz çerçevesinden bakıldığında insanların belli dönemlerde medyada yer bulan haberlere benzer yorumlar yaptığı gözlenmiştir. Bu gözlem veri setinde irdelenmiş ve dağılım grafiğinde en çok görülen duygu olan öfke etiketindeki örneklerine Şekil 6 ve Tablo 1 yardımı ile yer verilmiştir. Öfke duygusuna ait kelime 
bulutuna bakıldığında "sokağa", "çıkma”, "yasağı”," "kktc”, "sivil”,, "havacılık” vb. kelimeler göze çarpmaktadır. Bu kelimelerin belirginleşmesi süreç içinde yaşanan "sokağa çıkma yasağı ilan edilmemesi” ve "Kuzey Kıbrıs Türk Cumhuriyeti Sivil Havacılık Dairesi’nde çalışan bir bürokratın kızının diğer vatandaşlardan farklı bir muamele görmesi” olaylarına insanların ortak duygusal tepki olarak öfkeyi verdikleri ve medyada yer bulan bu haberlere benzer yorumlar yaptığı şeklinde yorumlanabilir.

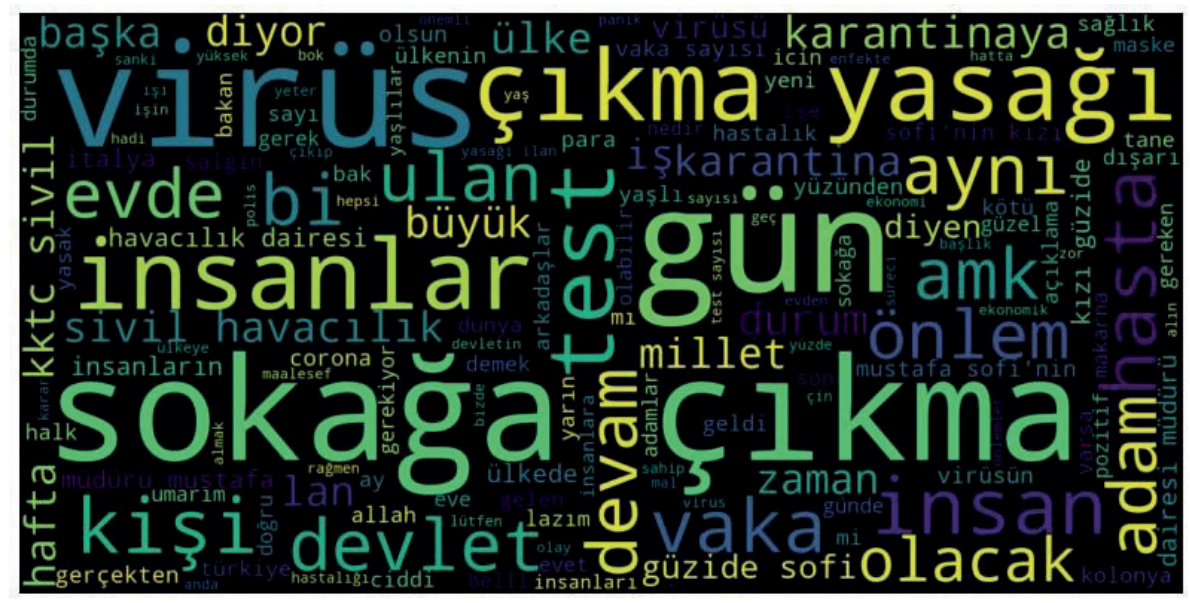

Şekil 6. Öfke etiketine ait kelime bulutu.

Tablo 1

"Güzide Sofi" hakkındaki haber ile ilgili yorumlar ve bunların benzerlik oranlart.

\begin{tabular}{lc}
\hline Cümle & Benzerlik Oranı \\
\hline görünüşler yanıltıcıdır sadece sesli düşünüyorum; alanlar maskeli polisler içeri gitmedikleri tedavi alınmış olabilir mi? kktc & 0.966 \\
sivil havacılık dairesi müdürü mustafa sofi’nin kızı güzide sofi açıllama bekleyen hakkına hukukuna girebilecek olaydır & 0.943 \\
kktc sivil havacılık dairesi müdürü mustafa sofi'nin kızı güzide sofi lanet olsun insanlığa köpek insan & \\
kktc sivil havacılık dairesi müdürü mustafa sofi’nin kızı güzide sofi açılanmazsa bugüne sağlık bakanının takdir gördüğü & \\
emekler çöpe gidecektir gözümde derhal rezillige bi açıklama yapılsı kılıf uydurulmasın açıklama yapılsın ihmali herkes & 0.933 \\
cezasın çeksin. & \\
\hline
\end{tabular}

Öfke duygusundan sonra veri setinde en fazla veriye sahip etiket beklenti etiketi olmuştur. Etiket incelendiğinde "Sokağa çıkma yasağı uygulanması" ile ilgili beklenti duygusuna çokça rastlanmıştır. Konu ile ilgili benzer cümlelere Tablo 2'de yer verilmiştir.

Örneklerde incelendiğinde benzerlik oranı en yüksek üç yorum için bu oranlar \%93 ve üzeri olarak gerçekleşmiştir. Bu oranlar yorumcuların "sokağa çıkma yasağı" ile ilgili öfkenin yanı sıra bir beklenti duygusu içinde de olduklarını göstermektedir. Sokağa çıkma yasağı özelinde veri seti dikkate alındı̆̆ında, yorumcuların bir kısmının bu yasağın ilan edilmemesine öfkelendikleri, bir kısmının ise bu konu hakkında beklenti içinde oldukları görülmüştür.

Doküman benzerliklerinin yanı sıra kelime benzerlikleri de ortak duyguların tespitinde kullanılabilecek yöntemlerdendir. Çalışmada kelime benzerlikleri de ortak duygu tespiti için word2vec yöntemi yardımı ile gerçekleştirilmiştir. Bu yöntem ile elde edilen sonuçlara örnek olarak “korkuyorum” kelimesine benzer kelimeler Şekil 7'de verilmiştir. Tablo 3’te ise Şekil 7'de yer alan “baban, evladım, başkası, sevdiğim” kelimelerinin benzerlik oranları yer almaktadır. Tablo 3 ve Şekil 7 birlikte değerlendirildiğinde yorumcuların yakınları, sevdikleri ve diğer insanlar için korktukları söylenebilir. 
Tablo 2

Sokağa çıkma yasă̆ı hakkındaki yorumlar ve bunların benzerlik oranları.

\begin{tabular}{|c|c|}
\hline Cümle & Benzerlik Oranı \\
\hline $\begin{array}{l}\text { kontrollü bir şekilde gelmesi gerektiğini düşünüyorum yukarıdaki arkadaş } 23 \text { hafta yazmış ama o zamana kadar çığından } \\
\text { çıkar market alışverişi dışında sokağa çıkılmamalı alışveriş için çıkılacağı zaman da belli bir limit olmalı ve maske } \\
\text { eldiven kombini ile markete çıkılmalı alışveriş yaptıktan sonra hem eldiven hem maske imha edilmeli ilk aşamada } 2 \text { hafta } \\
\text { ile sınırlı kalmalı corona semptomlarını gösteren kişiler için ayrı bir telefon hattı açılmalı } 112 \text { gibi bu kişilere evinde } \\
\text { test yapılıp pozitif çıkması halinde karantina hastanesine sevk edilmeli burada yazan çoğu kişi } 50 \text { yaş altında olduğu } \\
\text { için tuzumuz kuru bu önlemler bizlerden çok annelerimiz babalarımız yaşlı akrabalarımız için alınmalı yoksa maalesef } \\
\text { türkiye’yi büyük bir trajedi bekliyor }\end{array}$ & 0.975 \\
\hline en az 2 hafta kemiksiz amasız sokağa çıkma yasağı olmadan ülkenin süreci toparlayabileceğini düşünmüyorum & 0.974 \\
\hline $\begin{array}{l}60 \text { yaş üzerine sokağa çıkma yasağı gelmeli ihtiyaçları devletçe karşılanmalı bugün oransal olarak sokaklarda eskisinden } \\
\text { daha fazla yaşlı insan vardı } 60 \text { yaş üstü sokağa çıkma yasağı ilanı gerekliliği sars cov } 2 \text { pandemisi türkiye istatistikleri } \\
\text { ayrıca vaka sayısı } 1900 \text { 'da açıklansın kampanyası }\end{array}$ & 0.933 \\
\hline
\end{tabular}

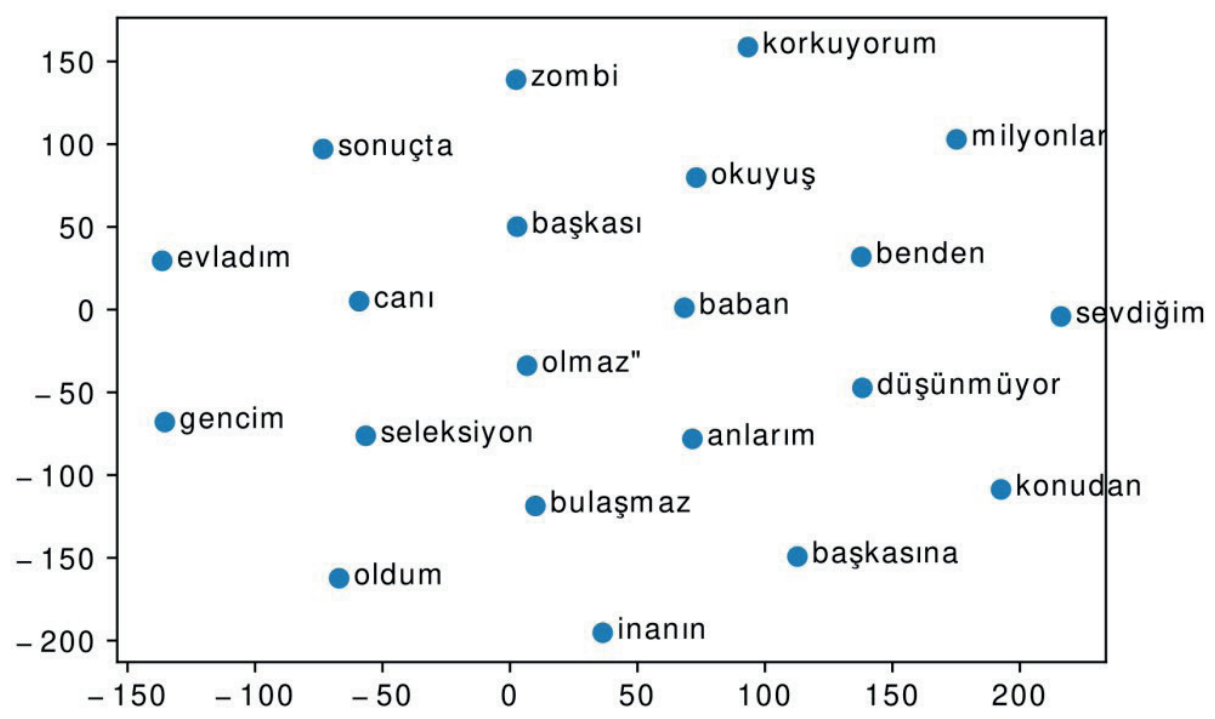

Şekil 7. Korkuyorum kelimesine benzer kelimeler.

Tablo 3

Korkuyorum kelimesi için benzerlik oranlarl.

\begin{tabular}{lc}
\hline Kelime Çifti & Benzerlik Oranı \\
\hline Korkuyorum - Evladım & 0.970 \\
Korkuyorum - Sevdiğim & 0.968 \\
Korkuyorum - Başkası & 0.969 \\
Korkuyorum - Baban & 0.836 \\
Korkuyorum - Annem & 0.794 \\
\hline
\end{tabular}

\section{SONUÇLAR}

Bu çalışma kapsamında ülkemizi ve tüm dünyayı etkileyen COVID-19 salgınının insanlar üzerindeki duygusal etkileri incelenmiştir. İnceleme için 11 Mart 2020 ile 31 Mart 2020 tarihleri arasında Ekşi Sözlük’te yer alan COVID-19 ile ilgili konu başlıklarından 7500 yorum toplanmıştır. Yapılan çalışmalar sonucunda insanların COVID-19 süreci ve yaşamlarında oluşan büyük değişiklikler karşısında hissettikleri duygu ve düşünceler tespit edilmeye çalışılmıştır. Bu tespit için veri setine gizli anlam analizi yöntemi uygulanmıştır. Bulgular ışı̆̆ında insanların öfke, kaygı, beklenti, güvensizlik gibi ortak duygusal tepkiler sergiledikleri sonucuna varılmıştır. Bu sonuç bize insanların beklemedikleri bu olay karşısında benzer tepkiler verebildiklerini göstermiştir.

Ayrıca çalışma kapsamında Doc2Vec ve Word2Vec yöntemleri kullanılarak duygu etiketlerindeki yorumların ayrıntıları da araştırılmıştır. Araştırma sonucunda pandemi sürecinde meydana gelen olaylara benzer duygusal tepkiler gösterildiği görülmüştür. Bu olaylara ilişkin verilecek örnekler, duygu etiketlerinin kelime bulutlarında yer alan en baskın kelimeler referans alınarak belirlenmiştir. Doc2Vec yöntemi yardımıyla öfke etiketine sahip “güzide sofi” olayını konu alan yorumların 
benzerlik oranları en yüksek 0.966 , en düşük 0.296 olarak gerçekleşmiştir. Beklenti etiketine sahip verilerde ise kelime bulutuna göre "Sokağa çıkma yasağı" konusu örnek verilmiştir. Bu konun en yüksek benzerlik oranı 0.975 olarak gerçekleşmiştir. Yorumlar ve bunların benzerlik oranları incelendiğinde modelin başarılı sonuçlar verdiği gözlenmiştir. Ayrıca kelime benzerliklerini temsil eden Word2Vec yönteminin sonuçlarına ilişkin örnekler de paylaşılmışıtır. "korkuyorum" kelimesi özelinde verilen örnek incelenmiştir. İnceleme sonucunda "korkuyorum özniteliğinin "evladım”, "sevdiğim”, "başkası", “baban”, “annem” öznitelikleri ile sırasıyla $0.970,0.968,0.969,0.836,0.794$ oranlarında benzerlik gösterdiği tespit edilmiştir. Bu tespitten yola çıkarak kullanıcıların yakınları, sevdikleri ve diğer insanlar için korktukları sonucuna ulaşılmıştır.

COVID-19 pandemisi süreci halen yaşanmakta olan dinamik bir süreç olduğundan dolayı çalışmanın devamında Nisan 2020 ve sonrasındaki verileri kapsayacak şekilde bir analiz gerçekleştirilerek aradaki farklar tespit edilebilir. Bunun yanı sıra, mevcut veri seti diğer algoritmalar yardımıyla sınıflandırılarak gelişmeler sağlanabilir. Ele alınan çalışma insanların Türkçe bir platform üzerindeki ifadeleri neticesinde doğal dil işleme yöntemleri ile yapılacak otomatik bir psikolojik durum tespiti çalışması için alt yapı oluşturabilecek niteliktedir ve bu kapsamda değerlendirildiğinde umut verici sonuçlara gebedir. Bunun yanı sıra çalışmanın Türkçe dilinde yayınlanan Türkçe bir platformdan elde edilen veriler yardımıyla yapılması çalışmanın özgünlüğ̈n̈ü ortaya koymaktadır.

Hakem Değerlendirmesi: Dış bağımsız.

Çıkar Çatışması: Yazarlar çıkar çatışması etmemişlerdir.

Finansal Destek: Yazarlar finansal destek beyan etmemișlerdir.

Yazar Katkıları: Çalışma Konsepti/Tasarım- A.Y., A.Y.O., Ü.Y., E.Ö.; Veri Toplama- A.Y., A.Y.O., Ü.Y., E.Ö.; Veri Analizi/Yorumlama- A.Y., A.Y.O., Ü.Y., E.Ö.; Yazı Taslağ1A.Y., A.Y.O., Ü.Y., E.Ö.; İçeriğin Eleştirel İncelemesi- A.Y., A.Y.O., Ü.Y., E.Ö.; Son Onay ve Sorumluluk- A.Y., A.Y.O., Ü.Y., E.Ö.

Peer-review: Externally peer-reviewed.

Conflict of Interest: The authors have no conflict of interest to declare

Grant Support: Authors declared no financial support.

Author Contributions: Conception/Design of Study- A.Y., A.Y.O., Ü.Y., E.Ö.; Data Acquisition- A.Y., A.Y.O., Ü.Y., E.Ö.; Data Analysis/Interpretation- A.Y., A.Y.O., Ü.Y., E.Ö.; Drafting Manuscript- A.Y., A.Y.O., Ü.Y., E.Ö.; Critical Revision of Manuscript- A.Y., A.Y.O., Ü.Y., E.Ö.; Final Approval and Accountability- A.Y., A.Y.O., Ü.Y., E.Ö.

\section{Kaynaklar/References}

Adalı, E. (2012). Doğal Dil İşleme. Türkiye Bilişim Vakfi Bilgisayar Bilimleri ve Mühendisliği Dergisi, 5(2).

Altintaş, V., Topal, K., ve Albayrak, M. (2019). Sosyal Medya Platformu Üzerinde Gizli Anlam Analizi. Avrupa Bilim ve Teknoloji Dergisi, (16), 863-869. doi:10.31590/ejosat.590521

Altszyler, E., Ribeiro, S., Sigman, M., ve Fernández Slezak, D. (2017). The interpretation of dream meaning: Resolving ambiguity using Latent Semantic Analysis in a small corpus of text. Consciousness and Cognition, 56, 178-187. doi:https://doi.org/10.1016/j.concog.2017.09.004

Bekaroğlu, E. (2019). Ölüm ve Hayatın Anlamı Üzerine Psikolojik Bir İnceleme: İvan İlyiç’in Ölümü. Ankara Hacı Bayram Veli Üniversitesi Edebiyat Fakültesi Dergisi, 1(1), 33-37.

Chang, W., Xu, Z., Zhou, S., ve Cao, W. (2018). Research on detection methods based on Doc2vec abnormal comments. Future Generation Computer Systems, 86, 656-662. doi:https://doi.org/10.1016/j.future.2018.04.059

Choi, J., ve Lee, S.-W. (2020). Improving FastText with inverse document frequency of subwords. Pattern Recognition Letters, 133, 165-172. doi:https:// doi.org/10.1016/j.patrec.2020.03.003

Dan-Glauser, E. S., ve Gross, J. J. (2015). The temporal dynamics of emotional acceptance: Experience, expression, and physiology. Biological Psychology, 108, 1-12. doi:https://doi.org/10.1016/j.biopsycho.2015.03.005

EkşiSözlük. (2020a). corona virüsü sayesinde fark edilen gerçekler, https://eksisozluk.com/corona-virusu-sayesinde-fark-edilen-gercekler--6435737, (Erişim Tarihi: 15.05.2020).

EkşiSözlük. (2020b). covid-19, https://eksisozluk.com/covid-19--6362411, (Erişim Tarihi: 15.05.2020).

EkşiSözlük. (2020c). covid-19 salgınını hafife alan gerizekalılar, https://eksisozluk.com/covid-19-salginini-hafife-alan-gerizekalilar--6406633, (Erişim Tarihi: 15.05.2020).

EkşiSözlük. (2020d). çocuk kişisiyle karantina günleri, https://eksisozluk.com/cocuk-kisisiyle-karantina-gunleri--6442390, (Erişim Tarihi: 15.05.2020). EkşiSözlük. (2020e). koronavirüs, https://eksisozluk.com/koronavirus--6335395, (Erişim Tarihi: 15.05.2020).

EkşiSözlük. (2020f). sars-cov-2, https://eksisozluk.com/sars-cov-2--6371913, (Erişim Tarihi: 15.05.2020).

EkşiSözlük. (2020g). sokağa çıkma yasağı, https://eksisozluk.com/sokaga-cikma-yasagi--45968, (Erişim Tarihi: 15.05.2020).

Gençöz, T. (1998). Korku: Sebepleri, sonuçları ve başetme yolları. Kriz Dergisi, 6(2), 9-16. doi:https://doi.org/10.1501/Kriz_0000000068

Gulati, K., Kumar, S. S., Boddu, R. S. K., Sarvakar, K., Sharma, D. K., ve Nomani, M. Z. M. (2021). Comparative analysis of machine learning-based 
classification models using sentiment classification of tweets related to COVID-19 pandemic. Materials Today: Proceedings, In Press. https:/doi. org/10.1016/j.matpr.2021.04.364

Hu, F., Xu, X., ve Li, L. (2019). Identifying word evolution by incorporating PoS and avoiding alignment of temporal words. Applied Soft Computing, 85, 105738. doi:https://doi.org/10.1016/j.asoc.2019.105738

İşleyen, A. (2019). İnternet, kamusal alan ve demokrasi: Ekşi Sözlük’te bedelli askerlik tartışmaları örneği. Nosyon: Uluslararası Toplum ve Kültür Çalışmaları Dergisi, 2, 50-63.

Jha, S., Prashar, D., Long, H. V., ve Taniar, D. (2020). Recurrent neural network for detecting malware. Computers \& Security, 99, 102037. doi:https:// doi.org/10.1016/j.cose.2020.102037

Kaya, M. (2020). Okul Müdürü Kavramına Yönelik Algıların Analizi: Bir Katılımcı Sözlük Fenomeni Ekşi Sözlük Örneği. Eurasian Journal of Teacher Education, 1 (1), 70-81 .

Khatua, A., Khatua, A., ve Cambria, E. (2019). A tale of two epidemics: Contextual Word2Vec for classifying twitter streams during outbreaks. Information Processing \& Management, 56(1), 247-257. doi:https://doi.org/10.1016/j.ipm.2018.10.010

Kim, D., Seo, D., Cho, S., ve Kang, P. (2019). Multi-co-training for document classification using various document representations: TF-IDF, LDA, and Doc2Vec. Information Sciences, 477, 15-29. doi:https://doi.org/10.1016/j.ins.2018.10.006

Kim, H. J., Kim, T. S., ve Sohn, S. Y. (2020). Recommendation of startups as technology cooperation candidates from the perspectives of similarity and potential: A deep learning approach. Decision Support Systems, 130, 113229. doi:https://doi.org/10.1016/j.dss.2019.113229

Kınık, D., ve Güran, A. (2021). TF-IDF ve Doc2Vec Tabanlı Türkçe Metin Sınıflandırma Sisteminin Başarım Değerinin Ardışık Kelime Grubu Tespiti ile Arttır1lmas1. Avrupa Bilim ve Teknoloji Dergisi, (21), 323-332. doi:https://doi.org/10.31590/ejosat.774144

Kundu, A., Jain, V., Kumar, S., ve Chandra, C. (2015). A journey from normative to behavioral operations in supply chain management: A review using Latent Semantic Analysis. Expert Systems with Applications, 42(2), 796-809. doi:https://doi.org/10.1016/j.eswa.2014.08.035

Le, Q. V., ve Mikolov, T. (2014). Distributed Representations of Sentences and Documents. arXiv:1405.4053. https://ui.adsabs.harvard.edu/ abs/2014arXiv1405.4053L

Li, L., Zhang, Q., Wang, X., Zhang, J., Wang, T., Gao, T., .. . Wang, F. (2020). Characterizing the Propagation of Situational Information in Social Media During COVID-19 Epidemic: A Case Study on Weibo. IEEE Transactions on Computational Social Systems, 7(2), 556-562. doi:10.1109/TCSS.2020.2980007

Li, S., Wang, Y., Xue, J., Zhao, N., ve Zhu, T. (2020). The Impact of COVID-19 Epidemic Declaration on Psychological Consequences: A Study on Active Weibo Users. Int J Environ Res Public Health, 17(6). doi:10.3390/ijerph17062032

Liu, B. (2015). Sentiment analysis: Mining opinions, sentiments, and emotions. New York: Cambridge University Press.

Lopez, C. E., Vasu, M., ve Gallemore, C. (2020). Understanding the perception of COVID-19 policies by mining a multilanguage Twitter dataset. arXiv:2003.10359. https://ui.adsabs.harvard.edu/abs/2020arXiv200310359L

López, W., Merlino, J., ve Rodríguez-Bocca, P. (2020). Learning semantic information from Internet Domain Names using word embeddings. Engineering Applications of Artificial Intelligence, 94, 103823. doi:https://doi.org/10.1016/j.engappai.2020.103823

Luo, J. W., ve Chong, J. J. R. (2020). Review of Natural Language Processing in Radiology. Neuroimaging Clinics of North America, $30(4), 447-458$. doi:https://doi.org/10.1016/j.nic.2020.08.001

Melton, C. A., Olusanya, O. A., Ammar, N., Shaban-Nejad, A. (2021). Public sentiment analysis and topic modeling regarding COVID-19 vaccines on the Reddit social media platform: A call to action for strengthening vaccine confidence. Journal of Infection and Public Health, 14(10), 1505-1512. doi: https://doi.org/10.1016/j.jiph.2021.08.010

Mikolov, T., Chen, K., Corrado, G., ve Dean, J. (2013). Efficient Estimation of Word Representations in Vector Space. arXiv:1301.3781. https://ui.adsabs. harvard.edu/abs/2013arXiv1301.3781M

Obembe, D., Kolade, O., Obembe, F., Owoseni, A., Mafimisebi, O. (2021). Covid-19 and the tourism industry: An early stage sentiment analysis of the impact of social media and stakeholder communication. International Journal of Information Management Data Insights, 1(2), 100040. doi: https:// doi.org/10.1016/j.jjimei.2021.100040

Özen, N. S., Saraç, S., ve Koyuncu, M. (2021). COVID-19 Vakalarının Makine Öğrenmesi Algoritmaları ile Tahmini: Amerika Birleşik Devletleri Örneği. Avrupa Bilim ve Teknoloji Dergisi, (22), 134-139. doi:https://doi.org/10.31590/ejosat.855113

Peng, H., Ma, Y., Poria, S., Li, Y., ve Cambria, E. (2021). Phonetic-enriched text representation for Chinese sentiment analysis with reinforcement learning. Information Fusion, 70, 88-99. doi:https://doi.org/10.1016/j.inffus.2021.01.005

Phung, N. M., ve Mimura, M. (2021). Detection of malicious javascript on an imbalanced dataset. Internet of Things, 13, 100357. doi:https://doi.org/10.1016/j. iot.2021.100357

Porsuk, A. Ö., ve Cerit, Ç. (2021). Sosyal Medyada Covid-19 Aşısı Tartışmaları: Ekşi Sözlük Örneği. Hacettepe Sağlık İdaresi Dergisi, 24(2): 347-360.

Sanz, I. P. (2020). Using the European Commission country recommendations to predict sovereign ratings: A topic modeling approach. Expert Systems with Applications, 5, 100026. doi:https://doi.org/10.1016/j.eswax.2020.100026

Shobana, J., ve Murali, M. (2021). Improving feature engineering by fine tuning the parameters of Skip gram model. Materials Today: Proceedings. doi:https://doi.org/10.1016/j.matpr.2021.01.536

Singh, J., ve Modi, N. (2019). Use of information modelling techniques to understand research trends in eye gaze estimation methods: An automated review. Heliyon, 5(12), e03033. doi:https://doi.org/10.1016/j.heliyon.2019.e03033

Soykan, Ç. (2003). Öfke ve öfke yönetimi. Kriz Dergisi, 11(2), 19-27. doi:https://doi.org/10.1501/Kriz_0000000192

Suleman, R. M., ve Korkontzelos, I. (2021). Extending latent semantic analysis to manage its syntactic blindness. Expert Systems with Applications, 165, 114130. doi:https://doi.org/10.1016/j.eswa.2020.114130 
Tahvili, S., Hatvani, L., Ramentol, E., Pimentel, R., Afzal, W., ve Herrera, F. (2020). A novel methodology to classify test cases using natural language processing and imbalanced learning. Engineering Applications of Artificial Intelligence, 95, 103878. doi:https://doi.org/10.1016/j.engappai.2020.103878

TDK. (2021). sözlük, -ğ̈̈, https://sozluk.gov.tr, (Erişim Tarihi: 06.12.2021).

Ünal Karagüvan, M. H. (1999). Açık kaygı ölçeğinin geçerlik ve güvenilirliği ile ilgili bir çalışma. Marmara Üniversitesi Atatürk Eğitim Fakültesi Ĕgitim Bilimleri Dergisi, 11(11), 203-218.

Yen, A.-Z., Huang, H.-H., ve Chen, H.-H. (2019). Learning English-Chinese bilingual word representations from sentence-aligned parallel corpus. Computer Speech \& Language, 56, 52-72. doi:https://doi.org/10.1016/j.cs1.2019.01.002

Yetiz, F. (2021). COVID-19 Pandemi Sürecinin Türk Bankacılık Sektörü Çalışanlarına ve Müşterilerine Etkileri: Swot Analizi. Avrupa Bilim ve Teknoloji Dergisi, (22), 109-117. doi:https://doi.org/10.31590/ejosat.835792

Zhu, B., Zheng, X., Liu, H., Li, J., and Wang P. (2020). Analysis of spatiotemporal characteristics of big data on social media sentiment with COVID-19 epidemic topics. Chaos, Solitons \& Fractals, 140(2020), 110123. doi: https://doi.org/10.1016/j.chaos.2020.110123 
